\title{
Multi Objective Time Table Scheduling Using Genetic Algorithm
}

\author{
Gegeo George \\ P G Student, Mangalam College of Engineering \\ gegeogeorge@gmail.com
}

\author{
Prof. Vinodh P Vijayan \\ Professor, Mangalam College of Engineering \\ vinodh.pvijayan@mangalam.in
}

\begin{abstract}
Scheduling the class periods using traditional methods like using online spreadsheets is complex and time consuming. The complexity increases with multiple subject, student and teachers as the requirements become more complex. It is difficult to manage subjects with multiple teachers or forming student groups and assigning teachers. In addition, priority of subjects or teachers, class hours are not considered for scheduling. Class scheduling using genetic algorithm, has been developed to schedule class rooms considering various resources and parameters. The proposed algorithm accepts various parameters like priority values for teachers and subjects or class hours and give the best solution. Our new system makes the classroom scheduling easier and also reduce the time required for scheduling.
\end{abstract}

Key words: Genetic, Classroom, Stakeholder

\section{INTRODUCTION}

Classroom scheduling was the most tedious and time-consuming process in every schools and colleges. Even though, there are software's available for scheduling, it does not meet many requirements needed by schools and colleges. Existing software's help to schedule class room by assigning subjects to teachers and teachers to class room. But it is impossible to get details about total hours assigned or to compare and analyze the work hours assigned with in a period.

Therefore, we propose a genetic algorithm for scheduling class rooms which reduces the complexity of the scheduling process. With the help of new system, the user can schedule classes, view and edit existing schedule. The genetic algorithm accepts multiple parameters, apply genetic operators to the parameters to find the best solution for the scheduling problem.

The algorithm takes various resources as input parameters as shown in figure 1 and find different score value for each population taken from input parameters. The population with the best score gives the optimal solution for scheduling.

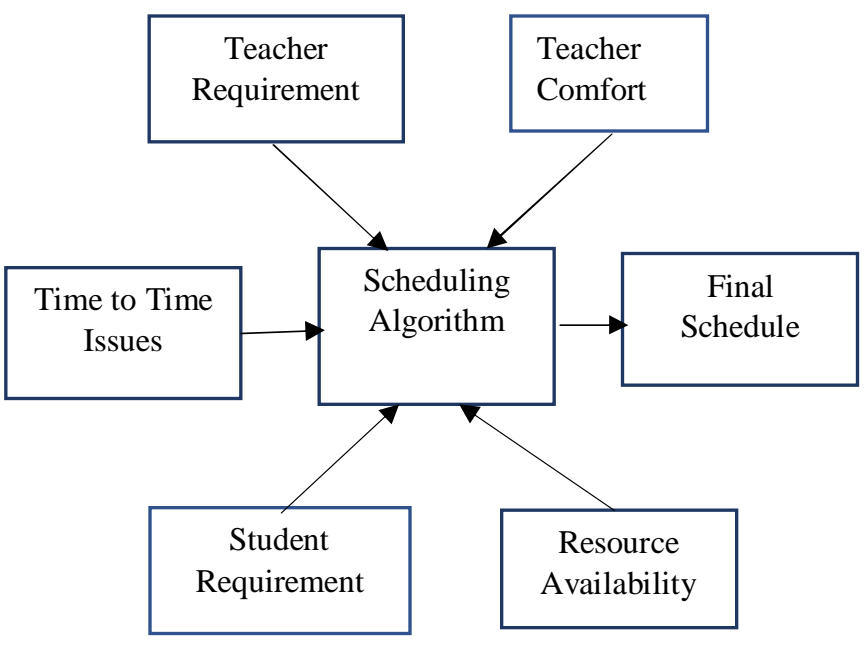

Figure 1: Multi Objective Time Table Scheduling Block diagram

\section{LITERATURE SURVEY}

Genetic algorithms are search algorithms based on the mechanisms of natural selection and natural genetics [1]. Genetic algorithms are used for solving problems because of its ability to search for optimal solutions in large search space [2]. In GA, it requires the natural set of parameters of optimization problem to be coded as a finite string length chromosome representation such as binary, real-coded, integer and permutation representation. Some operations have to do in genetic algorithm such as initialization, reproduction, evaluation and selection.

During initialization, some random solution is generated and store in population. The population itself is a collection of solutions and it will be forwarded for the next iteration. Reproduction is producing some other solutions through genetic operations, crossover and mutation. The crossover operation produces multiple child solutions and mutation is modifying the parent solution to become another solution. The algorithm will 
evaluate all existing solutions using the fitness function after the reproduction process is done. A fitness function is a function that will show how good a solution is. The solutions with the better fitness value are to be processed in the next iteration.

Different approaches are available for solving scheduling problem, however most of the systems are not customizable to provide users special needs [4]. It is important to consider that every organization must structure a schedule allocation system that favors the commitment, development and satisfaction of university professors, at the individual and collection level [3]. The process of scheduling the classroom is considered to be one of the most significant challenging procedures for programmers and teachers [5][6]. The optimization approach to time tables construction aims to optimize sets of general rules and find the best suited solution [3].

Even though, to deal with scheduling, different optimization methods i.e. particle swarm optimization (PSO), genetic algorithm (GA), ant colony system (ACS), fuzzy logic etc. have been used to obtain fast computing abilities, GA is the most suitable approach in the arrangement of scheduling system [4]. Genetic algorithms have the ability to search for optimal solutions in search space.

The growing complexity of the input factors is posing significant challenges to solve the classroom scheduling problem. Several significant constrained factors such as timing, teacher, lecture, classroom, and students must be considered [5][6]. It requires a lot of time and effort to make a practical and highly efficient classroom scheduling plan [6].

Each course may have one or more lectures and classes depending on the total number of students registered [4]. The scheduling method includes necessary constraints [6]

- A teacher cannot teach two classes at the same time;

- A student cannot follow two lectures at the same time;

- Some teachers must have at least one day off during the week (Optional);

- All the days of the week should be covered by the time table;

- Subject X must have exactly so-and-so hours each week;

\section{PROPOSED SYSTEM}

The system uses Genetic Algorithm for optimizing and finding best solution for class room scheduling. The algorithm accepts multiple parameters such as Class hours, Subject priority or priority values assigned to teachers. Considering these parameters as input, the algorithm calculates score values for different combinations of input. The result with best score is used for scheduling the class room.

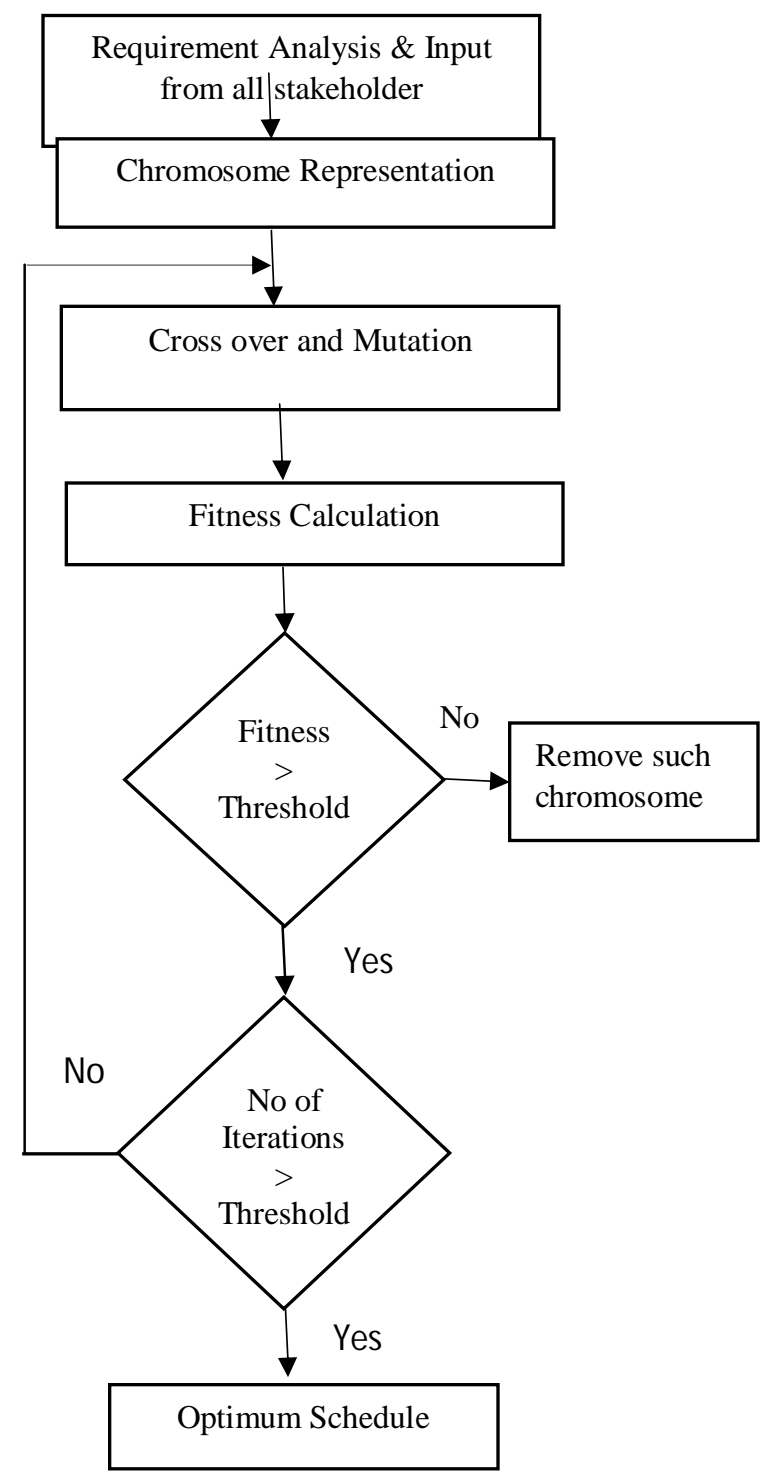

Figure 2: Flow chart of Schedule creation

We start with the requirement analysis and input from all stakeholders, where we represent inputs as chromosomes. We apply genetic operator's crossover and mutation to the input set and fitness is calculated. All chromosomes which does not satisfy the condition fitness greater than threshold are removed. We perform the above steps until number of iterations became greater than threshold. The overall process is shown in the figure 2. 


\section{EXPERIMENTS AND RESULTS}

The scheduling application is developed using Asp.Net Core, Angular, Angular CLI, Bootstrap, $\mathrm{C \#}$ and EntityFrameworkCore. MySQL is used as the back-end database. EntityFrameworkCore is used for connecting front end with the database.

Angular CLI is used for the front-end development and .Net Core is used for the API development.

With reference to the figure 3 , We can find that the convergence time decreases with the increase in mutation probability.

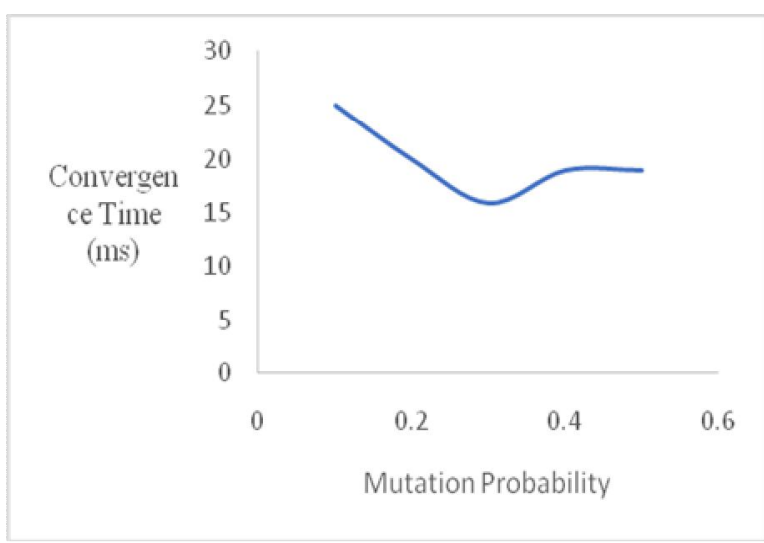

Figure 3: Mutation Probability and Convergence Time result

We can consider any number of parameters for the genetic algorithm. The experimental result shows that the user satisfaction is higher when we use large of parameters when compared to satisfaction with fewer number of parameters the same is plotted in the figure 4 .

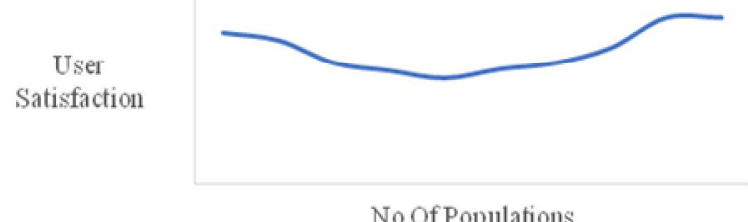

No Of Populations

Figure 4: User satisfaction level with no of populations

\section{CONCLUSION}

The real time issues like class scheduling in educational institutions are multi-objectives problems where multiple parameters like teachers input, students input, overall comfort etc need to be considered. The optimization of overall efficiency of the system using traditional algorithm are time consuming as well as end up with local optimum. The application of evolutionary algorithm like genetic algorithm will be able to operate in a dynamic scenario and bring global solution. The system gives improved user satisfaction rate along with reduction in convergence time.

\section{REFERENCES}

1. David E Goldberg. Genetic Algorithms in Search, Optimization and Machine Learning, $1^{\text {st }}$ ed. Addison-Wesley Publishing Company, Inc, 1989, Ch. 1, pp. 1-2.

2. Ruth Ema Febrita, Wayan Firdaus Mahmudy, Modified Genetic Algorithm for High School Time Table Scheduling with Fuzzy Time Window, 2017 International Conference on Sustainable Information Engineering and Technology (SIET), 24 - 25 Nov. 2017

https://doi.org/10.1109/SIET.2017.8304115

3. D. Calle-López, J. Cornejo-Reyes, F. PesántezAvilés, V. Robles-Bykbaev, M. Rodas-Tobar, C. Vásquez-Vásquez, A university administration system to automatically assign courses to teachers and support the design of timetables through mathematical modeling and restriction analysis, 2018 IEEE World Engineering Education Conference (EDUNINE), 11-14 March 2018 https://doi.org/10.1109/EDUNINE.2018.8451006 4. Nur Iqtiyani Ilham E.H Mat Saat, N.H Abdul Rahman, Farah Yasmin Adul Rahman, NurhaniKasuan, Auto-Generate Scheduling System Based on Expert System, $20177^{\text {th }}$ IEEE International Conference on Control System, Computing and Engineering (ICCSCE 2017), 2426 November 2017, Penag, Malaysia

5. Saket Khandelwal, Pallavi B, Bindushree D.C, An Innovative Approach of Classroom Scheduling: SmartClass: A Review, 2018 Second International Conference on Advances in Electronics, Computers and Communications (ICAECC), 9-10 Feb. 2018 https://doi.org/10.1109/ICAECC.2018.8479527

6. Chao Wang, Aili Wang and Xuehi Zhou, A Classroom Scheduling Service for Smart Classes, IEEE Transactions on Service Computing, Vol. 10, No 2, March/April 2017 https://doi.org/10.1109/TSC.2015.2444849 